\title{
Training U.S. Managers Bound for Different Cultures
}

\author{
Yezdi H. Godiwalla ${ }^{1}$ \\ ${ }^{1}$ College of Business and Economics, University of Wisconsin - Whitewater, Whitewater, Wisconsin, USA
}

Correspondence: Yezdi H. Godiwalla, Management Department, College of Business and Economics, University of Wisconsin - Whitewater, Whitewater, Wisconsin 53190, USA.

Received: November 20, 2015

Accepted: December 3, 2015

Available online: December 4, 2015

doi:10.11114/ijsss.v4i1.1234

URL: http://dx.doi.org/10.11114/ijsss.v4i1.1234

\begin{abstract}
Culturally distant countries pose greater challenges to a manager than culturally closer countries. The culturally distant countries challenge a manager to be better in dealing with: personal anxiety, stress, environmental differences and uncertainty; personal adjustment and adaption; communication and leadership with empathy in culturally distant countries; and personal/individual self-efficiency and motivation to tenaciously work for achieving goals.
\end{abstract}

Keywords: Training expatriates, MNC executives, managing across cultures, US managers abroad

\section{Introduction}

Foreign assignments for U.S. managers require additional and special preparation and training than do domestic assignments. Foreign assignments challenge a manager to adjust to strange or unfamiliar task environments. Preparing U.S. managers for foreign assignments is important because they have to be prepared for dealing with the different countries' unfamiliar work and non-working or social environments. The unfamiliar cultural and task environments of the foreign subsidiary of the multinational corporation (MNC) cause an additional adjustment challenge for the manager. He has to manage his foreign subsidiary organization in an unfamiliar work culture and operating system. The wide cultural distance between US and the host country of it foreign units pose an additional challenge to the US manager. He has to lead in a different work and social cultural setting, requiring him to exchange his approach, mind set and conduct.

The challenge to the US manager, as an individual, takes place in many forms and it has many consequences. These include: anxiety and stress because of unfamiliarity; ineffective problem solving; difficulty in managing cultural differences when it comes to his communication and establishing working relationships; problems in personal adaptation; and his not overcoming the obstacles achieving his or her full executive performance potential.

The US manager has to assess his own (subsequently, "he" or "his", expressly means "he/she", "his/her" and himself/herself) individual characteristics and capabilities; know his or her own personality; and, assess the foreign assignment, including the operating processes and problems of the foreign subsidiary. These issues would help to determine the precise content of his training. Further, he or she needs to gauge the cultural difference between U.S and the host country in order to determine his training for his social and cultural adjustment. This cultural or "soft" content of his training is vital for his or her leading in the host country social setting. The greater the cultural distance, the greater is the need for his preparation, adjustment and flexibility.

\subsection{Purpose}

The paper provides the U.S. manager's preparation or training goals and the scope of his task environment in his foreign assignment. The purpose of the paper is to provide the scope and extent of the expatriate training for a culturally distant foreign assignment and how the expatriate may pursue an effective training program. The challenge is particularly greater when the difference in cultural and operating environments between the expatriate's home country and the host country is unduly great. The expatriate would face greater unfamiliarity in his foreign assignment's task environment. The paper would highlight this challenge and provide an outline of effective expatriate training for overcoming the challenge.

\section{Global Competition and the Need for US Expatriate Training}

Global competition imposes greater challenges to an expatriate manager as other foreign companies enter a host country market. Zahra (2001) proposes a dual influence on an MNC's foreign subsidiary unit. An MNC may often pressure a 
strong corporate strategic mandate, implying a strong focus on an HQ approved global strategic plan. The other force is the influence of local environment of the host country and nearby regions that have an effect upon the MNC's foreign unit. In his study, Zahra (2001) found that both forces impose additional entrepreneurial expectation on the foreign subsidiary. This means the subsidiary would have to prospect for newer opportunities and deal with the issues of risks, threats and uncertainties emanating from the local and regional environments. The US expatriate would thus perform the role of an entrepreneurial manager of the subsidiary unit and seek to prospect for opportunities and newer and better ways of doing business. He or she would more than ever be dealing with his own anxiety and stress in view of the perceived environmental uncertainty. Global competition continues to place increasing pressures on MNCs to manage their international operations more effectively and entrepreneurially. The expatriate manager has to add more scope to his executive role.

Foreign sales have become increasingly important for most MNCs. Many depend on the diversification of sales from foreign countries. This is true as many emerging markets are booming in the developing world. They provide better growth opportunities. Growth rates in these countries have outstripped those in industrialized countries. MNCs with expanding geographic scope thus need to better manage their foreign operations. The use of expatriate managers has become vital in the MNC growth agenda. This places extra emphasis on the need for more effectiveness of expatriate managers and specialists, something that requires better attention to the expatriate's training. Luthans and Farmer (2002) explain the connection between increasing global competition and the greater need for expatriate training. They state the influence of increasing global competition: "As global competitive battles heat up, the importance of developing expatriate managers for international success should not be overlooked. In search of a competitive advantage, MNCs are increasingly devoting more attention and resources to cultural training as a way to improve job performance of their international assignees." Competition and global growth opportunities drive up the expatriate managerial performance expectation. It sharpens his skills and alertness to newer ways and better approaches.

The use of expatriate managers would result in better foreign subsidiary performance, and, therefore, lead to improved overall MNC global competitiveness. Their knowledge of MNC's strategies and operating systems helps in focusing on competitive advantage. This is also an area for the expatriate manager to improve his skills.

\subsection{Differences in Global Cultures: The Expatriate's Challenge}

Many industrialized countries have cultures and operating environments vastly that are different from those of the developing countries. This wide cultural gap poses a great challenge to the expatriate from countries such as US, UK, Germany and France. The expatriate has to be adaptable and self-confident in dealing with this big difference. The Lee and Croker (2006) study makes these observations: "(1) the greater the expatriate confidence and his adaptability, then the lower is the perceived need for expatriate training; (2) the greater the complexity of task, the lesser the capability of host managers and the greater the cultural difference, then the greater is the perceived need for the expatriate's training; and (3) the expatriate's learning preference and the expatriate's instructor's training methods would determine the need for training and effectiveness of training." This set of observations make an imminent need for more detailed and tailored training program for each manager bound for a foreign assignment.

\section{Training Expatriate Managers}

It is important to understand the needs of the foreign assignment: its specific challenges, expectations, work and cultural issues and the general expatriate task environments. Pre-departure knowledge of the foreign assignment and other issues like living conditions become important content of training of the expatriate. Social and cultural adaption and behavior modification are important prerequisites for a U.S. expatriate success. The importance of such content of the expatriate training is reviewed by many studies. Chang (2005) compiles the works of Tung (1982), Oddou (1991), Brewster and Pickard (1994), Frazer and Tucker (2007), Zakaria (2000), and Petranek (2004). In this cumulative context, Chang (2005) states: "Some of the more common features are cross-cultural training, communications (including language) training, clarification of performance criteria and expectation, cooperation and collaboration skills, managing stress and emotions, local logistics and everyday life issues, knowledge of the foreign subsidiary and its local environments." This cumulative fusion of the research of various scholars' points to the need for a more comprehensive approach of training a manager bound for a foreign assignment.

The expatriate would be challenged in his first weeks and months in the foreign assignment. He would have to quickly adjust to the host country people and environment. Pre-departure training of cultural sensitivity, communication and local language, behavioral flexibility skills, stress management, solving problems in strange environments, and leading and motivating in different cultures are some of the more important training items. Shin, Morgeson and Campion (2007) cite studies to indicate: "Communication competence, cultural empathy, interpersonal skills, and social interaction would improve cross-cultural adjustment to working and non-working environment."

There are two distinct phases of expatriate manager training: before departure from and, after arrival in the foreign 
assignment country. Pre-departure and post-arrival training are both very important and they complement each other. Pre-departure training would condition the expatriate as to what he can expect in the foreign assignment. This training would help him to understand the host country culture, communication, methods of operation and way of life. However, the real impact that would overwhelm the expatriate is after he or she arrives in the host country. Here he has to muster all his own innate intelligence together with his training in his home country. Here the guidance of a mentor would be of great help. Shin, Morgeson and Campion (2007) argue the benefits of the two stages of expatriate training; pre-departure and post-arrival: "First, in the pre-departure stage, organizations select and train individuals for expatriate assignments. Second, in the post-arrival stage, when expatriate workers begin to interact with host country nationals (HCNs) and adjust their behaviors to the host country's cultural norms and values for better performance, behavioral cross-training can be implemented to ensure that expatriates behave in culturally appropriate ways. (Further), behavioral training is more effective in the post-arrival stage because expatriates tend to be more motivated to learn once they are in their assignments." It may be pointed out that both stages of training are important and that training is continuous, in that the expatriate manager should treat himself as an ardent student of international affairs and international business even after coming to grips with the administrative duties of his foreign assignment.

\subsection{Individual Expatriate Self-Assessment}

The expatriate as an individual and given his unique personality, has to analyze who he is and also how and why he has his likes, dislikes, preferences, biases, opinions, and assumptions about all aspects of his foreign assignment. In so doing, he knows about his own point of reference as he perceives the host country's situation and people. This establishes in his mind his or her own position in the configuration of the different local cultural norms and behavioral practices. Varner and Palmer (2005) emphasize "the role of the individual, the importance of hierarchy, the importance of context in communication, and attitudes towards time and change."

In this context Varner and Palmer (2005) further provide a neutral comprehensive four phase expatriation adjustment process: "(1) potential expatriates are screened for personality characteristics . . contributing to expatriate success, (2) expatriates focus on developing a conscious self-awareness including their preferences, likes and dislikes, (3) potential expatriates study the other culture and their reaction to it, and (4) expatriates explore adaptation possibilities and strategies." Further, they also point out to the cognitive capability that is relevant to expatriate activity:

"Mental maps dictate how we react to events and people around us. In order to understand others, people need to explore their own cultural stereotypical thinking. Only after they have gained self-awareness can they develop a solid basis of cooperation." (Varner and Palmer, 2005). Expatriate adjustment is not just behavioral modification but it is more of an overall personality re-orientation, and that would include the re-organization of own's cognitive process.

\subsection{Individual Capabilities}

The individual expatriate's managerial capabilities are important. These are the capabilities as they are also assessed by his headquarters (HQ) in his home country context. These evaluations of managerial competence can be an important assessment for determining training content before the expatriate's departure to his foreign assignment. He would also be evaluated by his HQ supervisors and so he must know the criteria by which he will be evaluated.

Luthans and Farner (2002) make an important contribution that the expatriate should be viewed favorably from all sides of his role as a leader of the foreign subsidiary. They call this approach the "multisource 360-degree feedback system". Regarding it, they argue that it is "both a way to evaluate expatriate cultural training at behavioral and performance levels, as well as a way to develop expatriates to make them more effective once in the local culture." Their "expatriate management effectiveness questionnaire (EAEQ)" elicits perceived opinions of a person's "manager, subordinates and peers (hereafter referred to as "others") would be measured by items such as "This person is able to answer my questions" and "This person is technically competent.' Four dimensions used in the EAEQ are: (1) Technical Competence: "This person is able to answer my question"; (2) Management Skills: "Solve specific problems and contribute to MNC's broader goals", and their ability to plan, coordinate work, schedule resources, try new ideas, control and follow-up; (3) Interpersonal Skills: "capability to get along with and work through others in a caring way", "caring emphatic concern for everyone", "listening to my ideas and concerns," "recognizes and gives credit to others who deserve it"; and (4) Leadership Effectiveness: "expatriates desire and need confidence to lead and work through people to accomplish assigned duties. ...", and "The person is loyal and committed to this organization". They further add a fifth scale and a sixth scale: confidence/efficacy, and, cultural fit. Confidence/efficacy or "how well one can execute courses of action required to deal with prospective situations" in a highly task- and context-specific manner. These are important expatriate flexibility and adjustability dimensions that have important bearing on his adjustment and effectiveness. 


\subsection{Self-Efficacy and Personal Self-Monitoring}

In embarking upon learning, we start with ourselves. One's knowledge of oneself is the starting point for it gives an insight to oneself and a point of reference. "Know you" is the first step to plan for training of the expatriate. It is worthwhile to have a healthy self-confidence attitude that reflects a strong positive approach to whole heartedly face and solve any problem. This has a preemptive impact upon expatriate performance in his foreign assignment. It is useful to review literature on self efficacy because it is the spirited approach of the expatriate that would see him through difficulties.

Within reason, one must be self-sufficient as a person and be efficient within one's self. Studies on self-efficacy as well as self monitoring indicate that these two important dimensions help in effective expatriate adjustment or adjusting to any unfamiliar situation (Badura, 1992; Badura and Locke, 2003; and Gist and Mitchell, 1992). Self efficacy is "a person's belief about his ability to perform a particular task effectively" (Maurer, Weiss and Barbeite, 2003).

One's perceived self-confidence and self-assessment of one's capabilities for effectively performing the task at hand are relevant in this regard. Self-efficacy has powerful effects upon learning a new task, and, consequently, the performance of the task itself (Gist and Mitchell, 1992). Further, self efficacy directly influences learning process by: (a) the choice of task and learning goals and activities, (b) the nature and amount of effort for the task, and (c) the level and nature of persistence to master the task despite its strangeness or difficulty (Badura, 1982). Shin, Morgeson and Campion (2007) argue that there are extra demands upon an expatriate in foreign assignments for a more adjustment-oriented and achievement-oriented personality, as compared with an executive for domestic assignments. Studies by Mendenhall and Oddon (1985) and Black (1990), state the three dimensions for effective adjustment in foreign environment: "the relationship dimension; the perceptual dimension, and the self-dimension."

In a similar context, that of a manager getting results through his people, Shin, Morgeson and Campion (2007) state: "The relationship dimension refers to skills related to fostering of relationships with host nationals. For successful expatriate adjustment, it is essential to develop good relationships with HCNs. By maintaining proper relationships with HCNs expatriate workers are able to interact with them appropriately, to overcome problems and to perform assignments effectively." Therefore, an expatriate manager must effectively communicate with his people and lead them to better performance.

Personal attributes of sensitivity, understanding, empathy, kindness and, within reason, helpfulness not only would endear a person but also would increase his ability to influence, manage and lead others. In this context of communication and inter-personal interactions, Cui, van den Berg and Jiang (1998) believe that there are "significant relationships between communication competence, cultural empathy, social interaction, and cross-cultural adaptation. (Studies) suggested that relationship dimensions such as cultural empathy and interpersonal skills become important when dealing with cultural differences. A study found that better interpersonal skills were positively related to expatriates' adjustment to working and non-working environment in host countries." For an expatriate, inter-personnel skills and competence are paramount. They are often strong predictors of his expatriate success.

\subsection{Importance of Expatriate's Communication Skills}

Just as a manager in his domestic culture would communicate with people around him in achieving performance results he would have to work harder to communicate in a different culture. Communication is a key to effective managerial performance because it is through people that he accomplishes results. In a foreign assignment, the challenge is greater for the expatriate to analyze the organizational situation. Thus, communication, including a rudimentary working knowledge of the local language, would help him to better interact and foster good relationships with host country nationals in the foreign operations. By doing so, the expatriate will better acquaint himself of the operating situation and make more effective decisions. Good communication is the conduit through which he or she and his or her people can function as an integrated team. Language capability should be considered as an integral part of the communication skill enhancement training. Working knowledge of the host country's language is most helpful.

If the host country's main commercial and working language is not English, Shin, Moregson and Campion (2007) suggest that in the foreign assignment, the expatriate executive would need additional skill capabilities. They state:

"The work demands for social and perceptual skills, reasoning ability and adjustment and achievement-orientation personality will be higher in non-English speaking countries than in English speaking countries."

For this opinion, their supporting argument is:

“. . . because language is an essential communication medium, expatriates may need more social skills in non-English speaking countries than in English speaking so they can develop favorable relationships with HCNs via social interactions." 


\subsection{Stress Management and Problem Solving}

Foreign assignments place additional stress on an individual. High stress can inhibit problem solving capability. As students in an exam hall of a difficult subject, our minds can go blank when we are very afraid. It takes time to regain composure before we can focus on answering the exam questions. Similarly, the expatriate must learn to manage higher stress, and, to accept and tolerate moderately high levels of stress when he confronts strange situations. His stress, uncertainty, and anxiety feelings preclude him from correctly understanding and solving the work situations. His mentor can help him or her in managing his stress in the post-arrival stage.

Regarding this issue, Mendenhall and Oddou (1985) further studied the self dimension, self confidence and tolerance of stress.

“. . . (these) are closely related to individual's abilities and personality characteristics. This includes confidence in one's ability to deal effectively with foreigners and new surroundings." Xenophobia is the fear of anything foreign. It points to certain closed-mindedness of a person who is consumed with himself. "If anything is different, it must be wrong irrelevant or inferior," as an ethnocentric person may feel.

Accentuated stress would reduce problem solving and decision making abilities. In this context, Black, Gregersen, Mendenhall and Stroh (1999) state that a sudden exposure to unfamiliar surroundings would raise the level of the expatriate's stress that would significantly impair his effectiveness as an expatriate in the foreign country situation. Similarly, studies on stress by Payne (1994), Mahoney et al (1998), Matthews and Wells (1988), Priester and Clum (1993) and Fraser and Tucker (1997) show that cognitive breakdowns, such as lapses of memory, reasoning, retrieval and perceptions in difficult situations, cause stress levels to significantly go up. Increases in stress levels cause ineffectiveness in problem analyses, problem solving, and decision making and implementation of plans.

In such situations, the person does not correctly understand the logic of cause-effect relationships in a given problem situation nor the problem solving reasoning in the local culture. It would be doubtful if a person with this handicap would be an effective expatriate manager. Regard these issues, Shin, Morgeson and Campion (2007) state:

"In turn, such perceived uncertainty may lead to intolerance of anomalies and incongruities and a strong need for explanation of cause-effect relationships. Thus, these kinds of reasoning ability would be particularly important set of cognitive abilities for expatriate work. This suggests that expatriate work will have higher reasoning ability requirements than domestic work because of stress, uncertainty, and anxiety associated with unfamiliar situations."

In the context of stressful situations and how they can affect cognitive performance, Shin, Morgeson and Campion (2007) comment on stress literature to portray the importance of:

“. . . cognitive abilities as particularly important in stress-coping process. For example, studies have found a positive relationship between cognitive failures (failures of memory, reasoning and perception in everyday life) and stress susceptibility. In addition, it has been shown that problem-solving ability is negatively related to stress level. In a similar vein, uncertainty can be caused by an individual's inability to adequately structure or categorize information. In turn, such perceived uncertainty may lead to intolerance of anomalies and incongruities and a strong need for explanation of cause-and-effect relationships. This suggests that expatriate work will have higher reasoning ability requirements than domestic work because of stress, uncertainty, and anxiety associated with unfamiliar situations."

Caligiuri (2000) similarly "found that emotional stability was negatively related to the expatriate's desire to terminate their assignments." Other scholars (Harrison, Chadwick and Scales, 1996; Ones and Viswesvaran 1999; and Aycan, 1997) made similar findings about the important role that emotional stability (or equanimity) plays for the expatriate.

\subsection{Expatriate's Training Scope and Objectives}

The expatriate's training objectives are to build on the home country executive's existing capabilities. Such a training program may cover the generic expatriate for any international assignment as well as the specific country assignment. When we view the specific country assignment, we narrow the scope and concentrate on the particular country culture and the particular foreign assignment's needs. The objectives include: managerial skills in the particular host country setting; people skills in the host country, working knowledge of local language and communication skills; a longer term perspective that makes the expatriate more tenacious to look for enduring solutions not quick fixes; quick and effective adaptation to local culture, organizational situation and country's operating situation; decision making in the local setting; the work ethic that promotes quick and upswing learning curve; and the knack for avoiding initial costly mistakes through mentoring and communication with trustworthy local nationals about appropriate executive conduct. 


\subsection{Expatriate's Training Dimensions}

The expatriate's training must be tailor-made to focus on his unique individual needs and on his particular foreign assignment. These items of training include: knowledge about himself; self efficacy, self confidence, and a positive approach of surmounting any obstacle; better stress management and tolerance of uncertainty and anxiety; better adjustment-adaptability orientation; better achievement and goal accomplishment orientations; building better relationships through better empathy, sensitivity and understanding, and willingness to change one's behavior to accommodate host country's core values; knowledge of the task environment and social setting of the particular foreign assignment.

\section{Recommendations for the Content of US Expatriate Training}

The objectives for the US expatriate should be first clearly formulated for a particular foreign country assignment so that he or she may focus his or her training program for a specific foreign assignment. His pre-departure training and post-arrival mentoring focus on preparing or conditioning him to be effective and appropriate in the host country and regional context.

The pre-departure training objectives for the expatriate should be based upon his unique needs, his particular foreign assignment, and the operating circumstances of his foreign subsidiary. The expatriate's unique personal characteristics, past assignments and experience, skills, the nature of his openness to dissimilar cultures and foreign practices should be considered when formulating his training program. In addition, the considerations of his foreign assignment must be used to formulate his training program. The foreign assignment issues include the foreign country's details. These host country's details include: its history, culture, sub-cultures of the host country and its neighbors; life styles; infrastructure, economic, technical and business systems; social and business customs, protocol and etiquettes; and communication methods.

The expatriate's pre-departure training objectives should include:

1. Improving managerial leadership, particularly in the local host country cultural and operational context

2. Improving interpersonal skills in the host country cultural context

3. Improving communication, including language, skills in the host country context

4. Improving on a long term, strategic perspective for the foreign assignment so that the expatriate would want to "stay" with his assignment. This is even though the trend is now for expatriate assignments to be shorter rather than longer; a strategic, longer term horizon would enable an expatriate to have a greater feeling of being embedded in the local situation. This perspective is necessary for the expatriate to want to take greater ownership and tenacity to solve the difficult problems with lasting solutions

5. Improving flexibility and adaptation skills that would ease the transition to the host country cultural, logistical, industrial and commercial, and foreign remit environments

6. Improving on a greater understanding of the decision making skills that build on insights of the foreign unit people and local knowledge of the business situation

7. Improving quick learning capability of local methods, customs and etiquette so as to avoid initial costly or embarrassing mistakes

8. Improving on a better understanding of the host country's history and culture (and similarly of the neighboring countries of the regions) that would enable him to better understand the host country nationals and their neighbors

9. Improving on host country-specific leadership and goal setting and accomplishing skills and improving upon them for greater effectiveness.

Learning on the job, which would last for a long time, takes place upon arrival. Post arrival learning is actual learning, with live players and situations. The post-arrival mentoring is very important because the expatriate's learned content during the pre-departure training stage needs further guidance for its implementation. The early phases of the expatriate's post-arrival mentoring should be done by an experienced, mature international manager who has worked in the host or a nearby country. This approach would help the expatriate in the early months as the expatriate grapples with numerous issues and decision making challenges in the new unfamiliar surroundings and task environment. The expatriate also needs to balance or reconcile the MNC headquarters focus on the corporate and global perspective, on the one hand, with the host country environment situation, on the other hand (Zahra, 2001). Post arrival mentoring can alleviate stress, clearly focus on understanding and performing the foreign assignment, improve self-efficacy, and improve adjustment and interpersonal, and leadership performance. 


\section{Achieving the Expatriate's Training Objectives}

The expatriate's pre-departure training program should focus on himself as a person dealing with his internal self, dealing with other people, and dealing the tasks of managing activities in the host country environment.

In dealing with his own personality, he can become more effective as a person. These personality aspects include his or her managing his or her stress and anxiety. The unfamiliar work and non-work situations in his foreign assignment course cause increased perceived environmental uncertainty and personal anxiety and stress. The expatriate has to become facile in the cause-effect relationship in the host country cultural and operational context. Pre-departure training would condition him about how host country nationals make decisions, interact and conduct business. He should build his competence of problem solving through improved cognitive capability and improved communication with host country nationals. This calls on his part for a fuller awareness of the nature of host country's business customs, methods and processes. Cognitive capability in this context is important and it refers to his building a better repertoire of his reasoning and perception in everyday life, with a quick and lasting learning curve that relies on good memory and retrieval process. This approach would enable him to feel that he has a good command of his task environment, an important state of emotion that drives down his or her personal stress.

His self-efficacy and self-confidence are important for him to be effective. They would have a positive impact on his followers. He may have a strong track record as an effective manager in the domestic environment, yet he needs to further his confidence in himself for meeting the greater challenge in the unfamiliar task environment. Together with greater tolerance of stress, anxiety and uncertainty because of unfamiliar environment, he needs to be a more optimistic and confident person. He should have a firm mind set that radiates endless confidence that he can and will solve all problems in the foreign assignment, some of which may take a longer time. The more familiar he is with the problems of his or her foreign assignment before he leaves for the foreign assignment, the better will be his grasp to deal with the realities after his or her arrival in the host country.

For a more effective adjustment to the host country environment, he himself must be emotionally stable. His equanimity and staying cool and steady even in different or unfamiliar problem situations will be critical for him or her to solve problems. He must know himself better; know his own ways of dealing with his challenges, and his preferences and fears. He must develop a plan to improve his dealing with these emotions. He must self-monitor his improvement plan. Even when he is down, emotionally, he still must have an optimistic posture. He must develop a wider range of flexibility of his or her personal behavior and personal adjustment to varying social, task and logistical situations. His studying of the conditions - work and non-work - of the host country would be necessary in building and retaining such composure.

Effective expatriate performance would also depend upon his continuously building himself to be better on each of these dimensions:

1. Stronger adjustment-oriented personality that emphasizes improved personal emotional stability, self-control and self-monitoring, personal flexibility, and a greater capacity to tolerate uncertainty, unfamiliarity, stress and anxiety

2. Stronger achievement-oriented personality that relies on: (i) tenacity to focus on clearly set task and personal goals by overcoming obstacles; (ii) stronger initiative-ness to solve problems in the unfamiliar foreign situation; (iii) sustained higher personal motivation that relies on "cold" heat rather than hot emotion to solve problems through people, (iv) longer-term, strategic perspective of his foreign assignment that is built on the premise that he will stay with the problems wand not run away from them, (and a clear mandate from the MNC headquarters to this effect would provide him with the necessary support); and (v) pro-active and entrepreneurial focus for exploring newer opportunities that would benefit the foreign subsidiary beyond the short term.

His ability to accomplish performance through the local people is critical (particularly critical in the initial phases of his foreign assignment) to his expatriate leadership role. In this regard, he must continuously develop better communication skills, including a working knowledge of the local commercial language. He needs to become a better listener, be better at building cultural empathy and inter-personal skills, and be better in social interaction for working as a team player. His people skills will have to be even better in the foreign assignment than in his or her domestic assignment. When he is in the foreign assignment he would be to rely even more on the local people for gathering, sorting, interpreting information and for guidance in alternative courses or actions. He should not attempt to chart the detailed actions in isolation, but only in conjunction with local people. His people skills will be useful again as he improves his people's capabilities through training them. Further, if his foreign assignment is in a country where the working language is not English, then he would have to be even better in his social and perceptual skills, his reasoning ability, the adjustment and achievement 
orientations of his personality for him to overcome the language barrier.

\section{Conclusion}

A U.S. expatriate must pursue pre-departure training on: better understanding of him, self-motivation and self-efficacy; stress management; cross cultural adaptation, communication motivation and leadership; build local work and social relationships; seek effective skills of decision making in teams in the host country culture. His post-arrival mentoring must focus on dealing with stress and uncertainty; social situations in work and non-work environments; decision making in teams; and complex or unfamiliar problems in the task environments. Effective expatriate training is a prerequisite for effective expatriate performance.

Expatriates initially, at least, face more obstacles challenges, uncertainty, strangeness, and stress than to domestic managers. The initial stress upon arrival in the host country is because of the cultural differences, reduced situation understanding and coping capability, ineffective adaptation and problem solving, and reduced communication fluency and work relationship competence. The initial months, at least, are marked by a greater need for mentoring for dealing with local, culturally different people situations, such as, leadership, supervision, motivation, conflict, leadership, group dynamics, the local cultural context, and, communication in adjustment and achievement oriented drive.

Training objectives for the expatriates must address these issues:

1. Improve managerial, leadership, people and communication skills

2. Longer term, strategic perspective, with a fast learning curve

3. Better adaptation and achievement orientations personality

4. Know local culture, history, and decision-making process

The expatriate must keep continuously address these issues of his own self:

1. Improving on emotional stability, self-motivation, self-flexibility, self-efficacy, and, on coping with personal stress and anxiety and environmental uncertainty

2. improving on self-confidence, with a strong problem-solving orientation

3. Improving on being adjustment and achievement oriented personality, and, to taking initiative and setting desirable goals and tenaciously pursuing them

4. Continuously improving on communication and people skills through empathy and social interaction; and building relationships and gain insights of the host country culture, history and methods of working

5. Improving skills of leadership, effectiveness, goal setting and accomplishment endeavors.

Setting higher goals for personal growth and accomplishments would make his own motivational factor and drive keep him dealing with challenge. This approach would keep his foreign assignment fresh and meaningful to him. Because of the greater expatriate challenge he needs training before departure to his foreign assignment, and, mentoring after his arrival in the host country. Both, pre-departure training and post-arrival mentoring would help prevent initial embarrassing mistakes and also help self adjustment so that the expatriate can better concentrate on his goal accomplishment process.

Both pre-departure training and post-arrival mentoring are important. The pre-departure training focuses on developing (a) expatriate's personal capabilities (self-confidence, self-motivation, self-discipline and monitoring, stress management, goal orientation and constancy of purpose despite difficulties and uncertainties); (b) building relationships through good communication and empathy in the local context; and (c) improving his or her problem analyses and solving skills in different countries. Post-arrival mentoring from a veteran guide would facilitate his rapid adjustment to the host country culture and foreign subsidiary's organizational realities. A mentor's guidance would prove invaluable to his getting started in the right way and to make sure that he focuses on the content of his task earlier and more fully. It would also ensure that the expatriate follows the tenet that learning is a continuous process, that he would forever keep on improving and fine tuning his skills and seek for greater effectiveness as an expatriate manager.

\section{References}

Acyan, Z. (1997). Acculturation of expatriate managers: A process model of adjustment and performance. In A Acyan (editor), New Approaches to Employee Management, Greenwich, CT: JAI Press, 4, 1-40.

Badura, A. (1982). Self efficacy mechanisms in human systems. Journal of Applied Psychology, 37, $122-147$.

Badura, A., \& Locke, E. A. (2003). Negative self-efficacy and goal effects revisited. Journal of Applied Psychology, 88, $87-89$. 
Black, J. S., Gregerson, H. B., Mendenhall, M. E., \& Stroh, L. K. (1999). Globalizing People through International Assignment. Reading, MA: Addison-Wesley.

Brewster, C., \& Pickard, J. (1994). Evaluating expatriate training. International Studies of Management and Organization, 3(24), 18-35.

Caliguiri, P. M. (2000). The big five personality characteristics as predictors of expatriate's desire to terminate the assignment and supervisor-rated performance. Personnel Psychology, 1(53), 67-88.

Chang, W. W. (2005). Expatriate training in international non-governmental organizations: A model for research. Human Resource Development Review, 4(4), 440-463.

Chao, G. T., \& Sun, Y. J. (1977). Training needs for expatriate adjustment in People's Republic of China. In A. Aycan (editor), New Approaches to Employee Management, 4, Greenwich, CT: JAI Press.

Cui, G., Berg, S. V., \& Jiang, W. (1998). Cross-cultural adaptation and ethic communication: Two structural equation models. The Howard Journal of Communications, 1(9), 69-85.

Frazer, K. P., \& Tucker, C. M. (2007). Individualization, stress and problem-solving abilities of college students. Journal of College Student Development, 38, 461-467.

Gist, M. E., \& Mitchell, T. R. (1992). Self-efficacy: A theoretical analysis of its determinants and malleability. Academy of Management Review, 17, 183-211.

Harrison, J. K., Chadwick, M., \& Scales, M. (1996). The relationship between cross-cultural adjustment and personality variables of self-efficacy and self-monitoring. International Journal of Intercultural Relations, 6(20), 167-188.

Lin, Y. Y., Carol, \& Wei, Y. C. (2005). An Eastern and SME version of expatriate management: An empirical study of small and medium enterprises in Taiwan. The International Journal of Human Resource Management (London), August, 8(16), 14-31.

Li-Yueh L., \& Robert, C. (2006). A contingency model to promote the effectiveness of expatriate training. Industrial Management and Data Systems, 8(106), 1187.

Luthans, K. W., \& Steve, F. (2002). Expatriate development: The use of 360-degree feedback. The Journal of Management Development, 9-10(21), 780-795.

Maurer, T. J., Weiss, E. M., \& Barbiete, F. G. (2003). A model of involvement in work-related learning and developmental activity: The effects of individual, situational and motivational age variables. Journal of Applied Psychology, 4(88), 707-724.

Mendenhall, M. E., \& Oddou, G. (1985). The dimensions of expatriate acculturation: A review. Academy of Management Review, 1(10), 39-47.

Mendenhall, M. E., \& Gunter, K. S. (2000). Expatriate training and development: Where do we go from here? Human Resource Management, Summer/Fall, 2-3(36), 251.

Oddou, G. R. (1991). Managing your expatriates: What the successful firms do. Human Resource Planning, 4(14), 301-308.

Ones, D. S., \& Viswesvaran, C. (1999). Personality determinants in the prediction of aspects of expatriate job success. In A. Aycan (editor), New Approaches to Employee Management, 4, Greenwich, CT: JAI Press.

Payne, R. (1994). Individual differences in the study of occupational stress. In C. L. Cooper and R. Payne (editors), Causes, Coping, and Consequences of Stress at Work, 209-232. New York, NY: John Wiley \& Sons.

Petranek, G. F. (2004) Global human resource development: The four C approach. Human Resource Development Quarterly, 2(15), 249-252.

Priester, M. J., \& Clum, G. A. (1993). Perceived problem-solving ability as a predictor of depression, hopelessness, and suicide ideation in a college population. Journal of Counseling Psychology, 1(40), 79-85.

Prud'homme, van Reine, Peter, \& Fons, T. (2000). Invited reaction: Developing expatriates for the Asia-Pacific region. Human Resource Development Quarterly, Fall, 3(11), 237-244.

Selmer, J. (2000). A quantitative needs assessment technique for cross-cultural work adjustment training. Human Resource Development Quarterly, Fall, 11(3), 269-282.

Shin, S., Frederick, J., Morgeson, P., \& Michael, A. C. (2007). What you do depends on where you are: Understanding how domestic and expatriate work requirements depend upon cultural context. Journal of International Business Studies, January, 1(38), 64-83. 
Suutari V., \& David, B. (2001). The role of on-site training and support expatriation: Existing and necessary host-company practices. Career Development International (Bradford), 6(6), 298-312.

Tung, R. (1982). Selection and training procedure of US, European and Japanese multinationals. California Management Review, 1(25), 57-71.

Varner, I. L., \& Teresa, M. P. (2005). Role of cultural self-knowledge in successful expatriation. Singapore Management Review, 1(27), 1-26.

Wynne, M. (2006). The hidden cost of expatriate executives. Global Cosmetic Industry, October, 10(174), 49-50.

Zahra, S. A. (2001). Entrepreneurship in the Multinational Corporation: The effects of corporate and local contexts. Academy of Management Proceedings, G1-G6.

\section{(cc) $\mathrm{EY}$}

This work is licensed under a Creative Commons Attribution 3.0 License. 